\title{
CONSTRUCTION PLANNING SIMULATION AT GRU AIRPORT
}

\author{
Marcelo Moretti Fioroni \\ Luiz Augusto G. Franzese \\ PARAGON Decision Science \\ Rua Arminda, $93-5^{\text {th }}$ floor \\ 04545-100, São Paulo - SP, BRAZIL
}

\author{
Marcello Costa \\ Andre Kuhn \\ Exército do Brasil - DOC/DNIT \\ Quartel General do Exercito, B1. B - 2th floor \\ 70630-901 Brasília - DF, BRAZIL
}

\begin{abstract}
Many complex construction schedules are still being planned nowadays with deterministic project schedule tools such as MS Project, with deterministic estimates, lack of focus on event conflicts and no queuing estimates. This paper presents a discrete-event simulation approach for a soil replacement project of great importance to the Brazilian government. This was part of the expansion work at GRU Airport, the greatest and most important of the country, and was being carried by the Brazilian Army. The airport should be ready for the increasing demand expected for World Cup in 2014 and Olympics in 2016. The study started with the original deterministic schedule, and considered several external factors, like traffic, rain seasons and providers capacity. After evaluating many scenarios and identifying some bottlenecks, the best scenario was found, with a due date sooner than initially planned.
\end{abstract}

\section{INTRODUCTION}

Project planning and scheduling is traditionally made using deterministic information. Even more sophisticated tools use the same principle. The principle of using deterministic information to plan is not wrong. Since future prediction is impossible, an estimative must be made based on previous experiences or information about the process.

However, present technologies like discrete-event simulation can assist this process, changing from the current "plan and hope for the best" to "plan and be aware the risks involved". To apply that, information about the processes variation can be used to simulate the planned schedule. Even a small variation can have a great impact on the plan, since the schedule may suffer a cascade effect where a delayed task delays the next, with its own variation, and follows, with surprising results not easily predicted with traditional scheduling tools.

In their study, Borrmann et al. (2009) observe that many decisions regarding necessary construction resources are made on the basis of experience from previous projects, leading to over or underestimating capacities. They also present a simulation-based solution, focused on a more operational short-term schedule for roads construction. A building construction simulation study was presented by Schramm \& Formoso (2007) using Arena, a general simulation tool. The same tool was used by Cabrera (2010) to test different scenarios for a construction schedule, from pessimistic to optimistic situations. A methodology for construction simulation studies is presented by Tang et al. (2011), considering the development of a traditional schedule tool like Critical Path Method or Linear Scheduling Method as a step for the simulation study. The importance of using a traditional planning tool like MS-Excel or MS-Project as the initial starting point for the simulation study is also reinforced by Lucko et al. (2009). This is a natural path, since the discrete-event simulation is not a scheduling tool itself, but is a valuable tool to test a preexisting schedule under different conditions, providing very accurate and valuable information regarding the number of resources necessary and due date estimation. 
Assuring the due date is a critical subject for the Brazilian government, since the country will host both the soccer World Cup in 2014 and the Olympics in 2016. The country has to be prepared for a great number of tourists coming to these events, providing proper infrastructure for security, lodging, airports and transportation in general. A great investment effort is being made by the government to achieve that, with special attention given to the airports. The Brazilian Army, as one of the most reliable and efficient institutions in the country, was given the responsibility for some of the most critical constructions regarding infrastructure. That was the case of GRU Airport, the biggest and most important international airport in the country that is currently completely overwhelmed by the regular traffic and clearly would not support the increasing passenger flow coming for the World Cup or Olympics.

\section{THE PROBLEM}

The GRU International Airport, well known in Brazil as Guarulhos airport because of the name of the city where it is located, is the greatest and the most important airport in the country. The expansion project planned will increase its capacity by at least 33\%. Currently, it has two passenger terminals, and a third one should be constructed.

The original schedule created on MS-Project expected to finish the work in 28 months, on time for the planned events. The simulation study would confirm this term, or test alternatives, if not.

The great engineering challenge is to replace the current soil, which is wet and inappropriate to support heavy planes, by a high quality soil, recycled from that location or transported from somewhere else. Guarulhos, as part of São Paulo metropolitan area, suffers a lot of traffic problems. The army team expected to have problems by adding a large truck fleet to that traffic, both to the city and to the working plant. In addition, there are different alternatives for wet soil disposal areas that should be evaluated, as well as the required space to temporarily store the original HQS (high quality soil).

The strategy for doing that in a large area is to divide it in columns, each one of them assigned to a team fully equipped to perform all necessary activities on that column. Figure 1 shows the original state of the airport with only two terminals. Figure 2 is an artistic preview of the third terminal, showing the area where the soil has to be replaced, divided in columns.

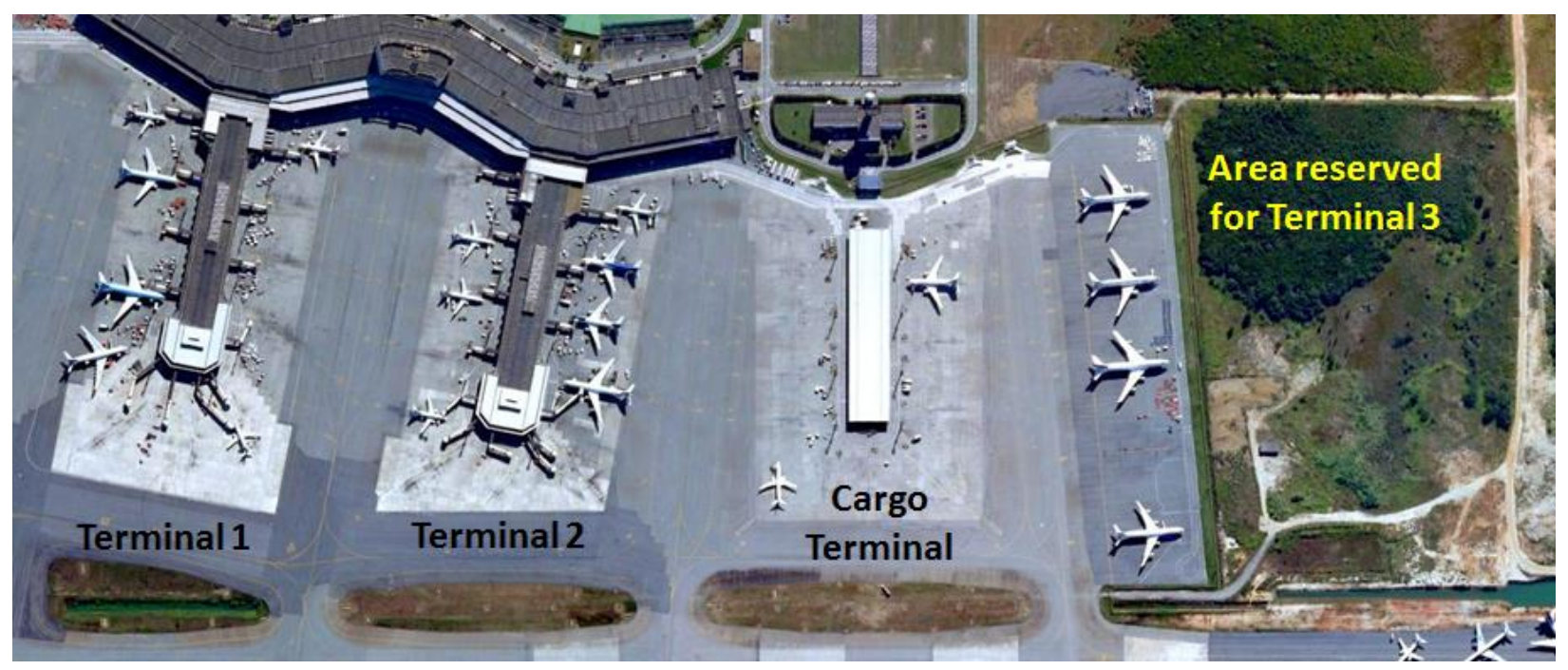

Figure 1: Original state of GRU Airport with two passenger terminals. 


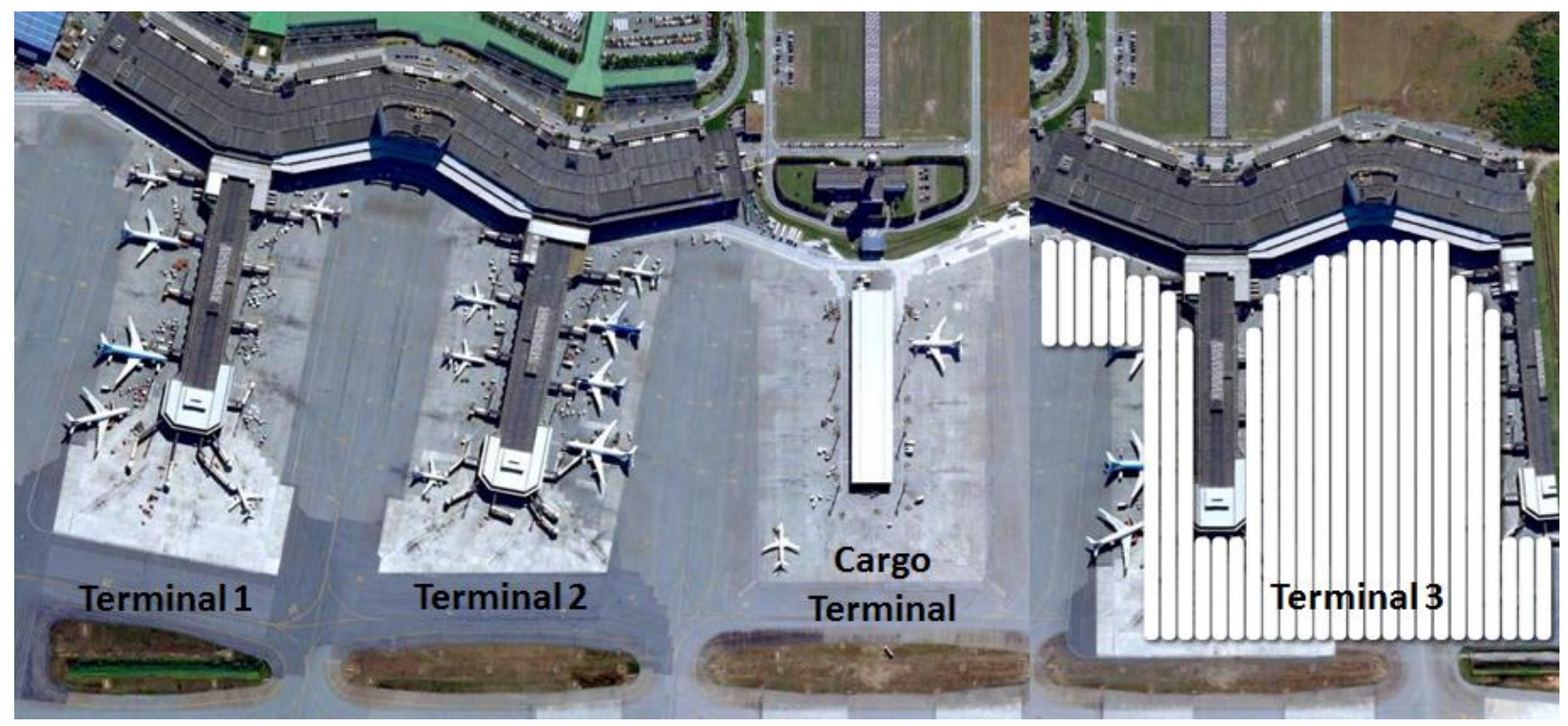

Figure 2: Conceptual art of the $3^{\text {rd }}$ terminal and the area where the soil has to be replaced.

\subsection{The Soil Replacement Plan}

The process of soil replacement has four stages that should be made in this sequence:

1. Removal of the superficial high quality soil (HQS) and store it in a nearby location.

2. Removal of the wet soil (WS) and dispose it in a nearby location.

3. Fill in with rocks.

4. Return the original HQS from the storage location or bring new HQS to cover the area.

The trucks are unable to pass over either the wet soil or the rocks, only over the HQS. Since they need access to the working area, the entire column area should not be dug at once, but rather in "trenches". Each column was divided into four trenches. When a trench started to be dug, the immediate subsequent trench should not start work, or should finish its current work to have the HQS finally returned. Figure 3 shows all columns divided in trenches, with the teams (identified by colors) already assigned.

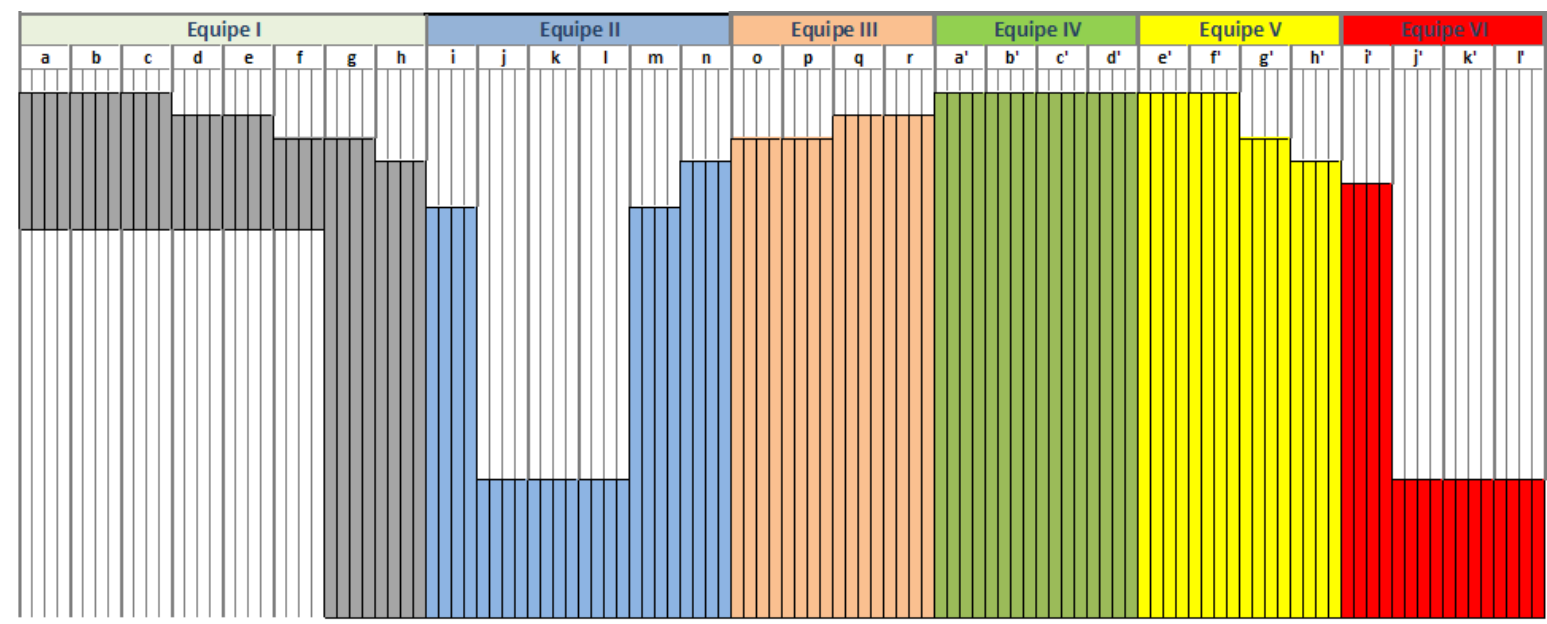

Figure 3: Columns divided in trenches and with the teams assigned. 
To allow truck access continually to the trench being worked, a working sequence (the schedule) was made. Each team is responsible for the trenches on its "column". Figure 4 illustrates this sequence for one team.

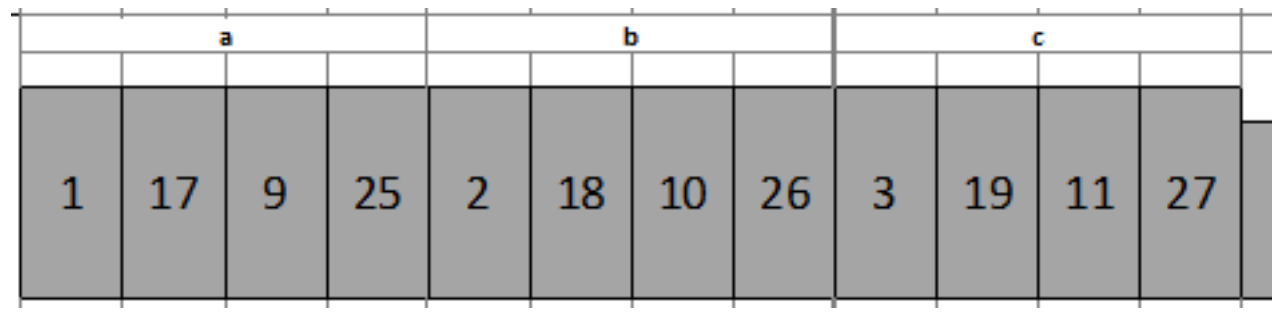

Figure 4: Excerpt of the trench work schedule for one team.

\subsection{The Material Handling Process}

The material handling activities should take into account:

- Number of trucks,

- Number of excavators used to remove the wet soil and HQS,

- Number of tractors used to fill the trenches with rocks,

- Number of rolls used to cover the trench with HQS,

- Traffic problems changing dynamically along the day (rush hours, etc.),

- Location of rock providers (3 alternatives),

- Location of HQS providers (3 alternatives),

- Location of wet soil disposal areas (2 alternatives),

- Airport gates to be used (3 alternatives), each one of them giving access to different roads outside the airport, and

- Internal storage area usage for HQS.

The simulation study should determine fleet sizes and set of providers that must be chosen to achieve the scheduled due date (28 months ahead).

\section{THE SIMULATION STUDY}

\subsection{Input Data}

Considering the schedule and the sequence of activities as an assumption not subject to change, the study focus on the flexible parameters, like the number of resources and providers, and a few other choices regarding the internal material movement. The primary focus was on the equipment directly involved on each trench. A model was developed with the Arena simulation package, well described by Bapat and Sturrock (2003).

To improve the process of creating new scenarios and examining its results, a user interface was developed in MS-Excel. The user fills in the parameters in the spreadsheet to create the scenario and the spreadsheet allowed the user to see the simulation results.

Part of the input interface is shown in Figure 5, which keeps the position of the columns, making it a user-friendly task. The impact of the traffic on system performance is also considered by informing the speed on each pair origin-destination, at different hour slots, as seen on Figure 6.

Each schedule entry also has an input called "index of completion", meaning how much of the current activity must be completed before the following activity could start. The most conservative option is $100 \%$. 


\section{Fioroni, Franzese, Costa, and Kuhn}

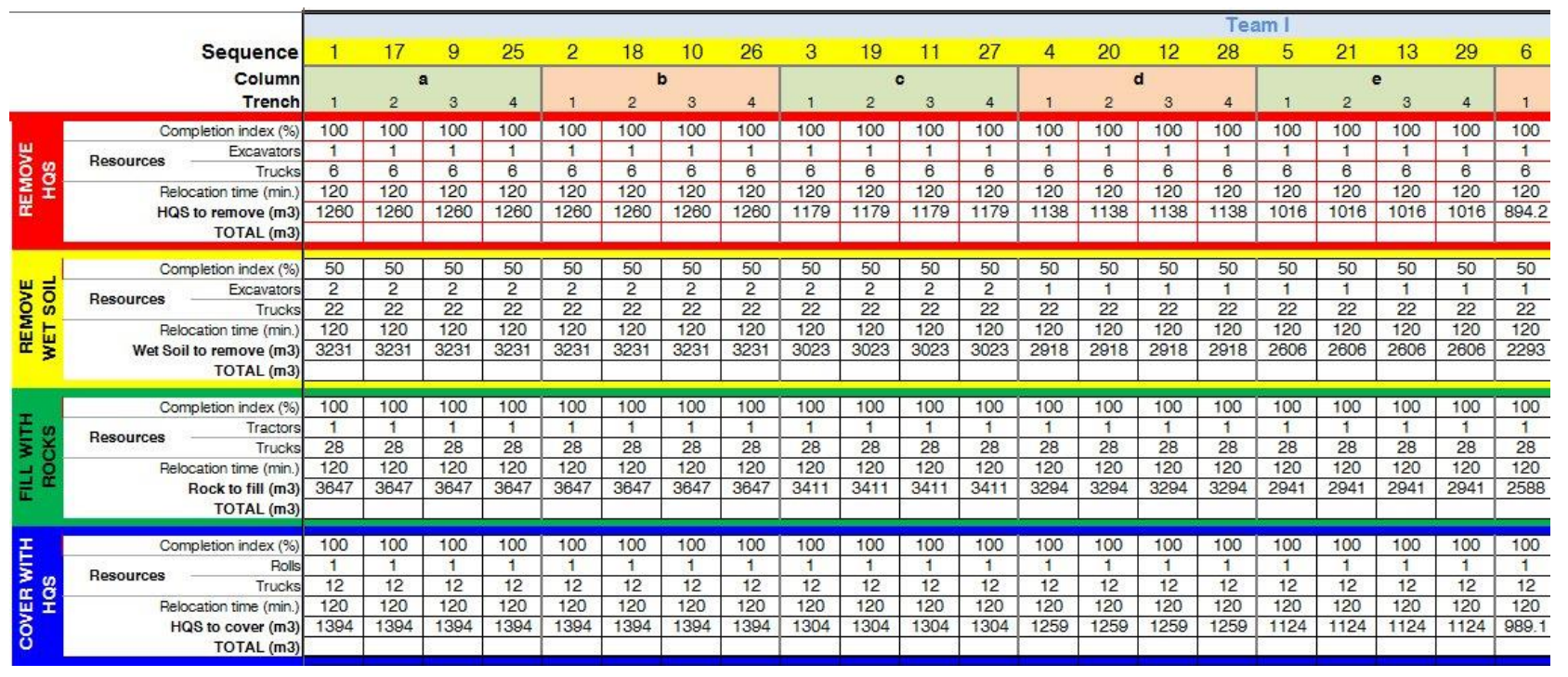

Figure 5: Partial view of the input user interface.

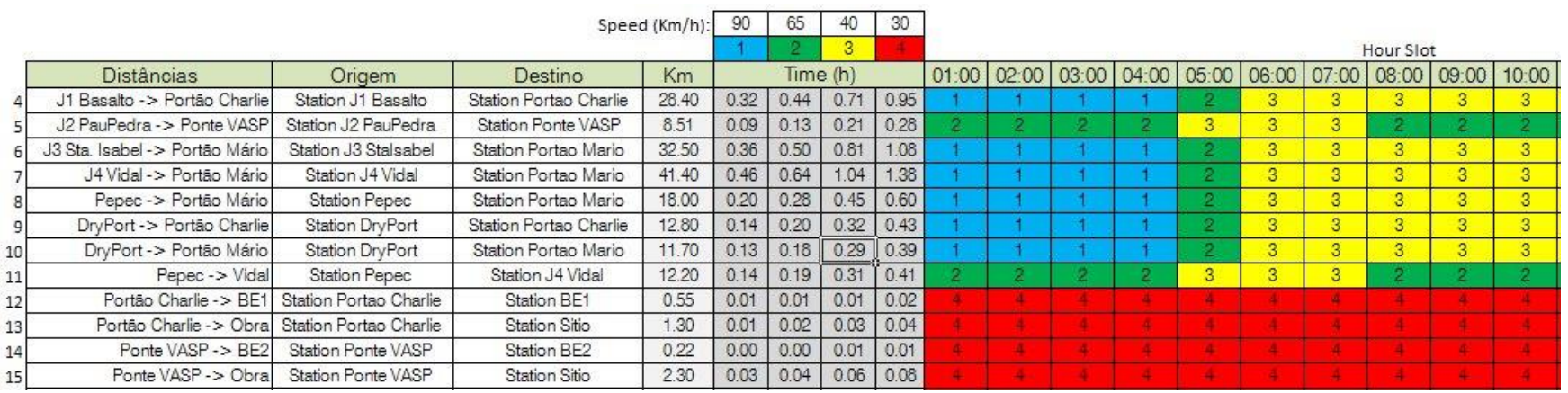

Figure 6: Partial view of the travel time data, per hour slot.

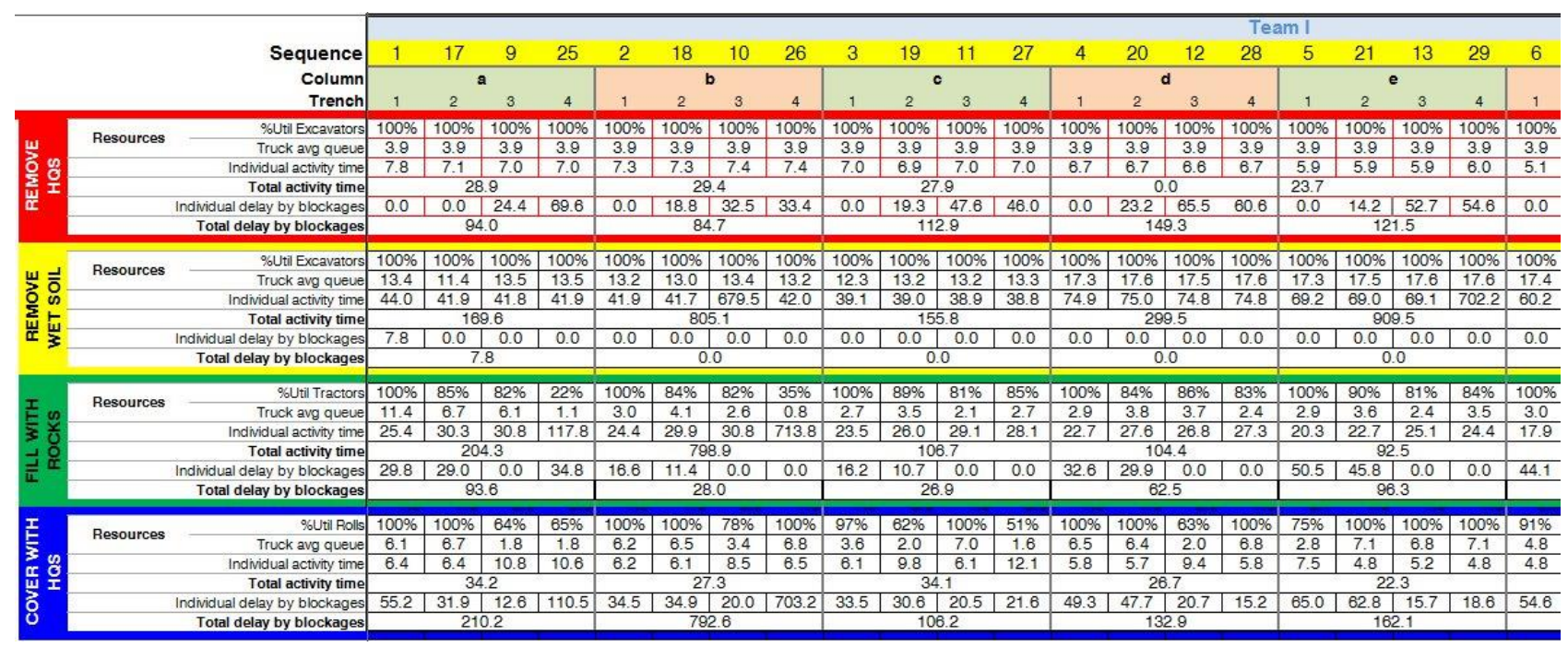

Figure 7: Partial view of the schedule execution KPIs. 


\subsection{KPI Recording}

The model records key performance indicators and provide them to the user interface, making them easier for the user to analyze. Figure 7 shows the results from a scheduling execution, which is presented in the same format as the input interface.

The most important KPIs to support choosing the best scenario were the ones regarding resource utilization, and the total time to finish the work. Other KPIs were used for model validation and verification purposes.

\subsection{The Model}

The model was built in the Arena simulation package, and includes an animation of the process as presented on Figure 8 . The animation helped to verify and validate the model, and was crucial when presenting the idea to the government and military personnel.

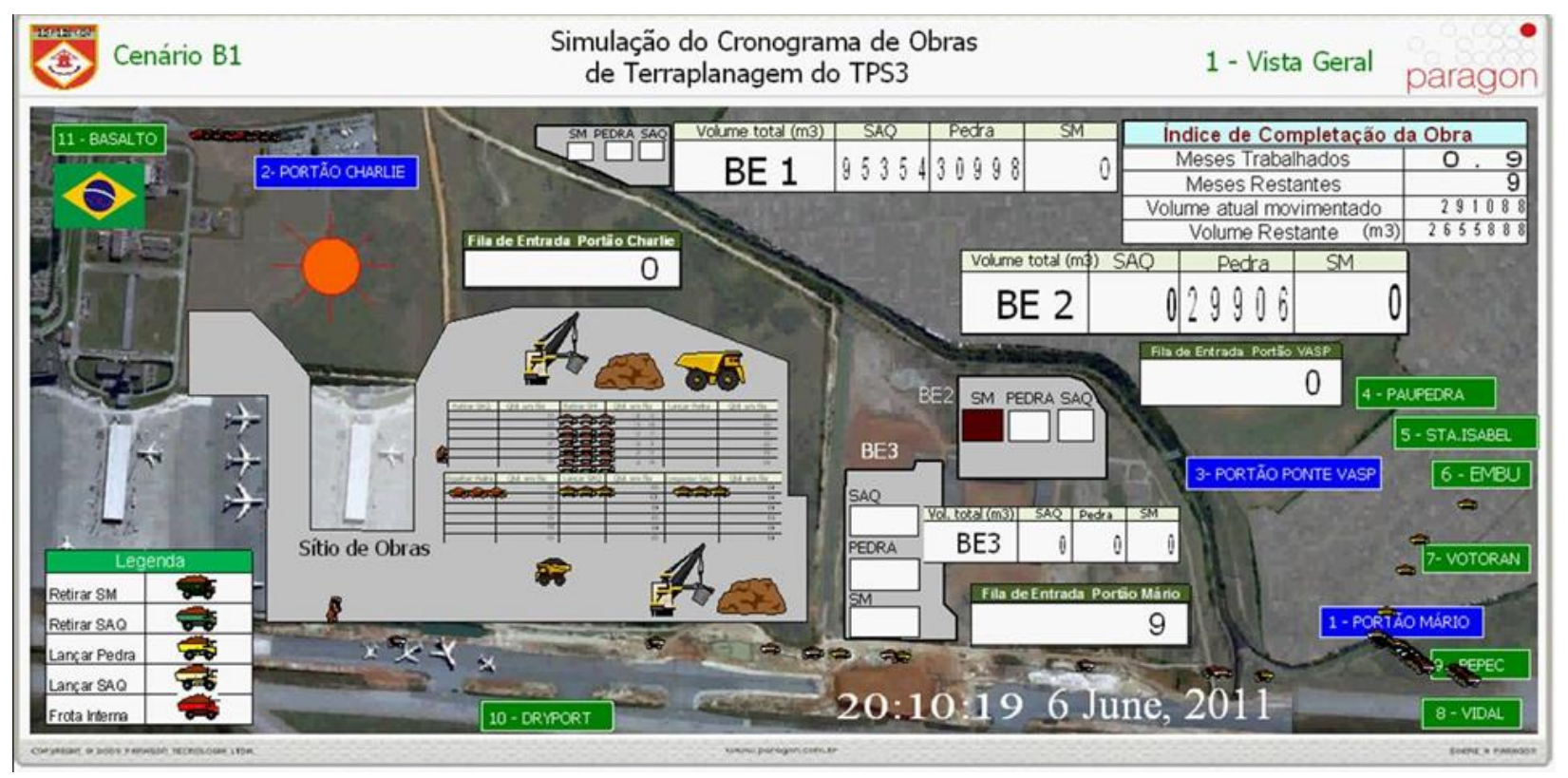

Figure 8: Model animation.

The model was divided in two main parts: the construction yard process and the logistic process, both interacting during the simulation run.

The yard process reproduced the construction schedule in detail. Each task have its own requirements to be executed, like tractors and other equipments, and the availability of trucks providing raw material, or empty trucks to receive the removed material, depending on the task. Like the real system, all six teams were working in parallel to advance in its own area, while are being supplied by the trucks.

The logistic process represents all material movement required to perform the work, using a truck fleet. The trucks are responsible to move raw material to the yard, or to get rid of removed material. The airport area have three entry/exit gates that could be used by the trucks, each one of them generating different impact to the surrounding traffic. Also, different destination options are available, depending on the material being transported.

Since there was no real system to collect the data for process times and delays, other construction yards were used as a reference. Many data were available only as average values, and a variation was estimated based on the Army experience. 


\section{Fioroni, Franzese, Costa, and Kuhn}

Figure 9 below presents an schematic of the model structure, with both systems interacting. Figure 10 shows part of the model logic in Arena, and Figure 11 the animation of soil replacement progress.

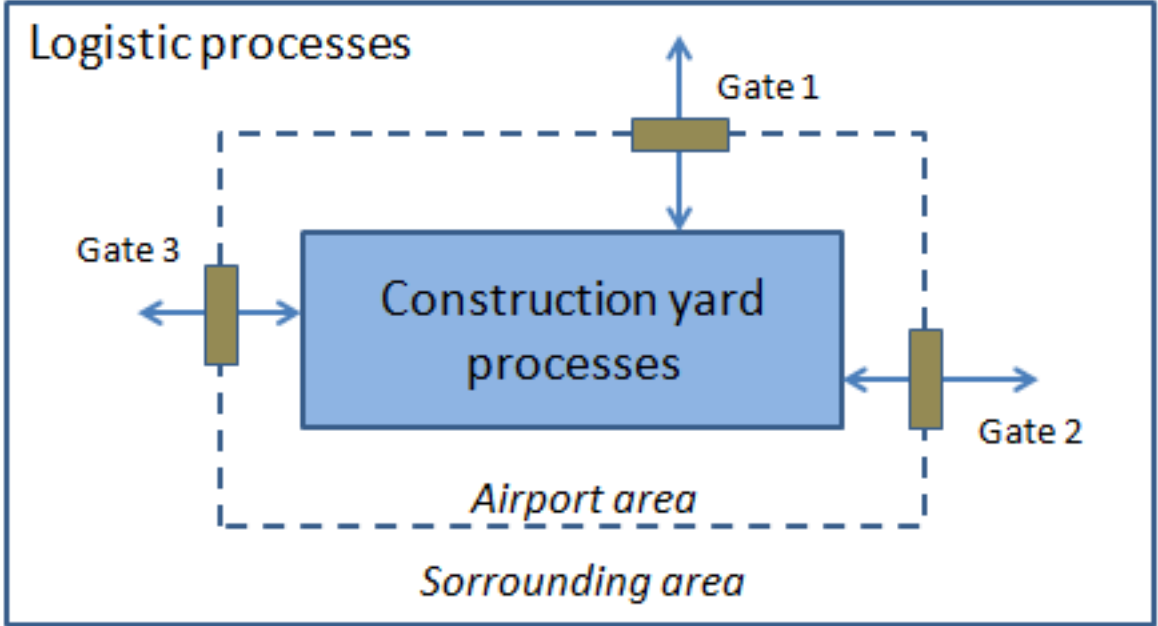

Figure 9: Model structure.

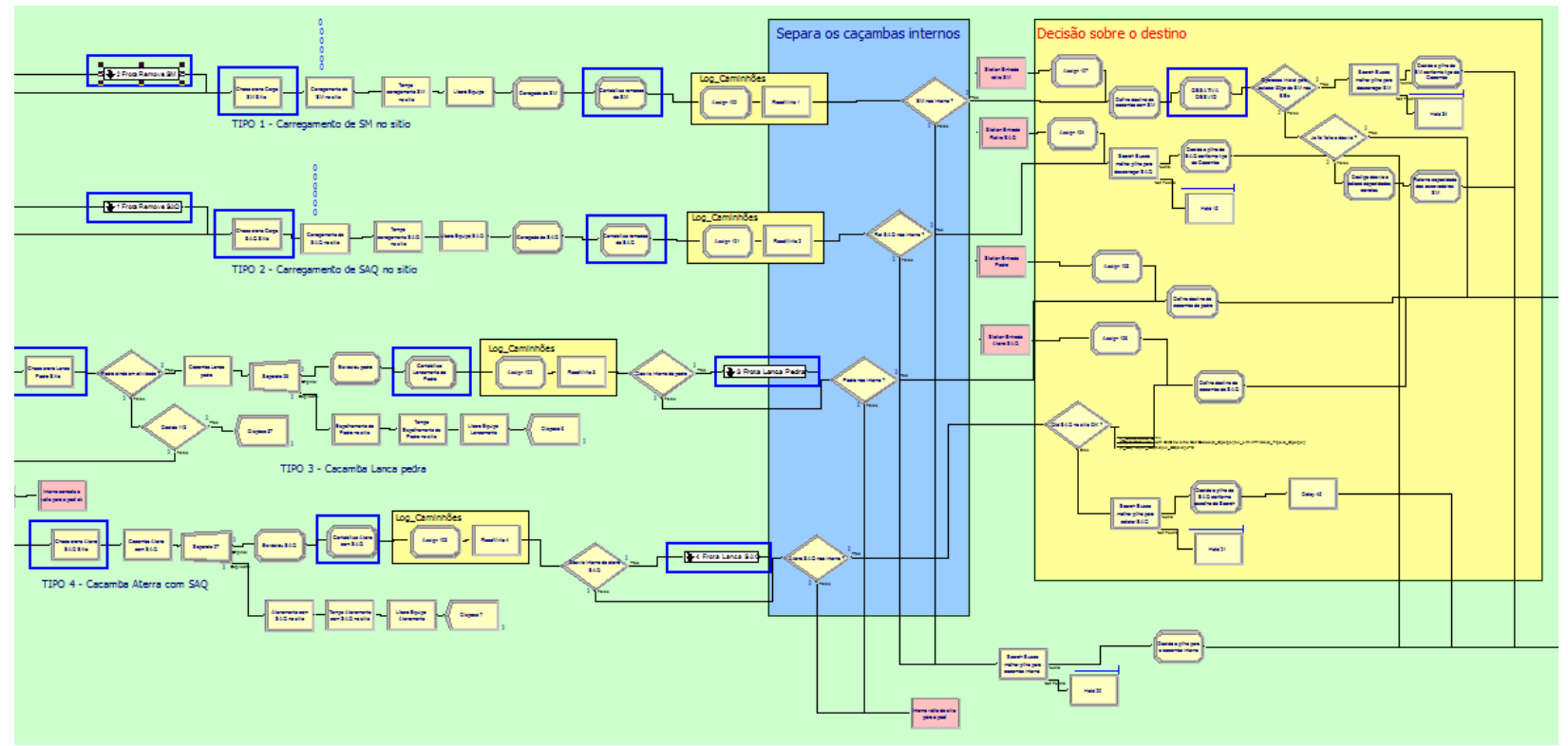

Figure 10: Partial view of the Arena model code. 


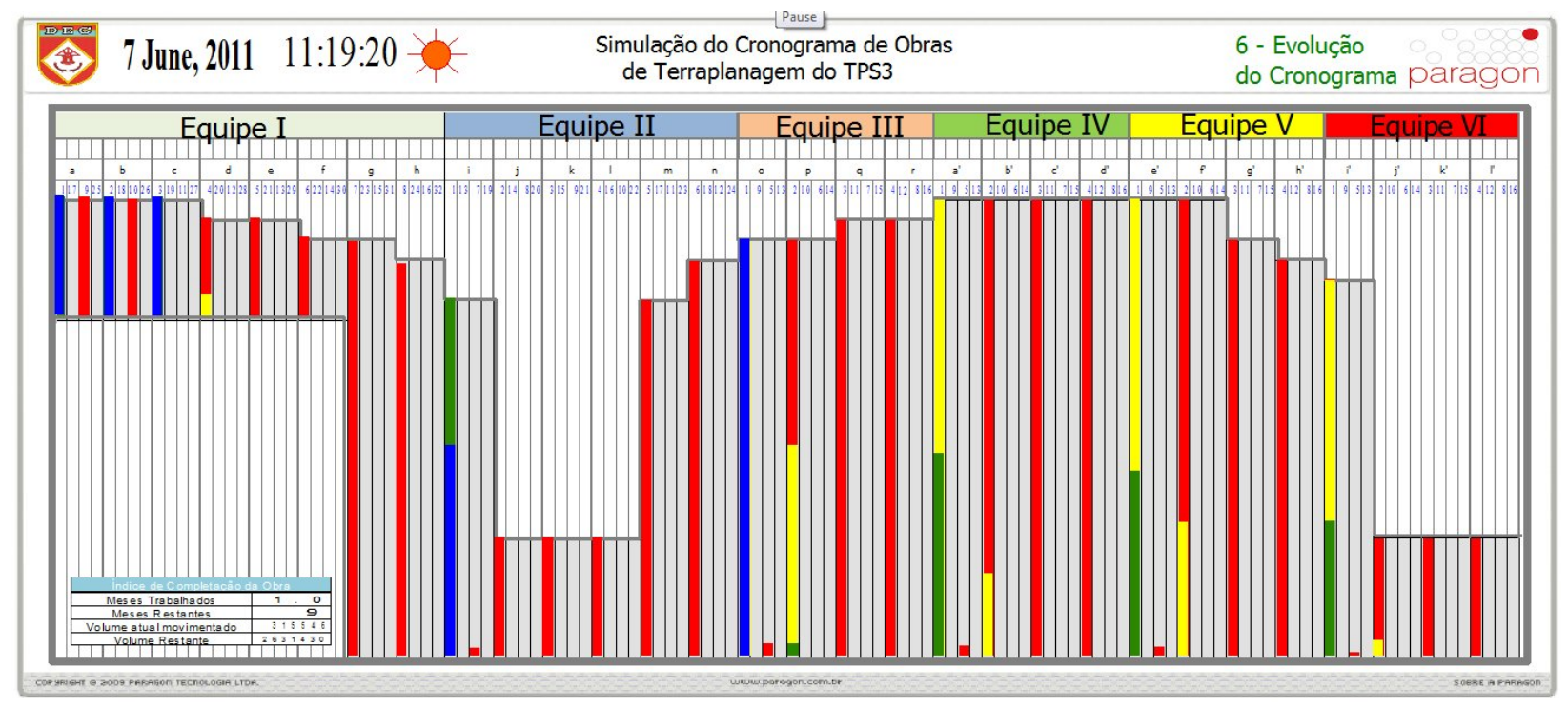

Figure 11: Animation of the soil replacement progress.

- The construction yard simulation is linked with the logistic simulation by some requirements, like:The rock preparation, made by tractors, can only be performed if a certain amount of rock is available. That rock is provided by the trucks, The same is valid to HQS (high quality soil).

- The low quality soil removal can only be performed if an empty truck is available to receive the material.

Using this approach, a large range of factors were considered, giving great confidence to the results.

\section{THE RESULTS}

The experimentation process was divided in two phases. The first set of experiments (Phase I) had the goal to check the feasibility of the original schedule, and if the due date would not be achieved, to determine the main system bottleneck. The Phase II experiments had the goal to test alternatives for the bottlenecks, in order to end the project on time.

The experiments showed two major problems. First, the original schedule would end 8 months after the desired due date. Second, the schedule assumed an ideal supply of rocks and HQS, but when simulating under real conditions, the delay would be even greater, ending 19 months after the due date.

The main bottleneck proved to be the rock supply. The supplier had no capacity to deliver at the required rate. The scenario comparison can be seen on Figure 12. Two scenarios ended before the due date, exactly that ones with additional resources at the suppliers. The red columns mean the number of rain periods, when the system had to stop all activities.

Since the rock providers were outside the system scope, the best scenarios for Phase I were unfeasible. Increasing the provider's capacity was not an option. 
Fioroni, Franzese, Costa, and Kuhn

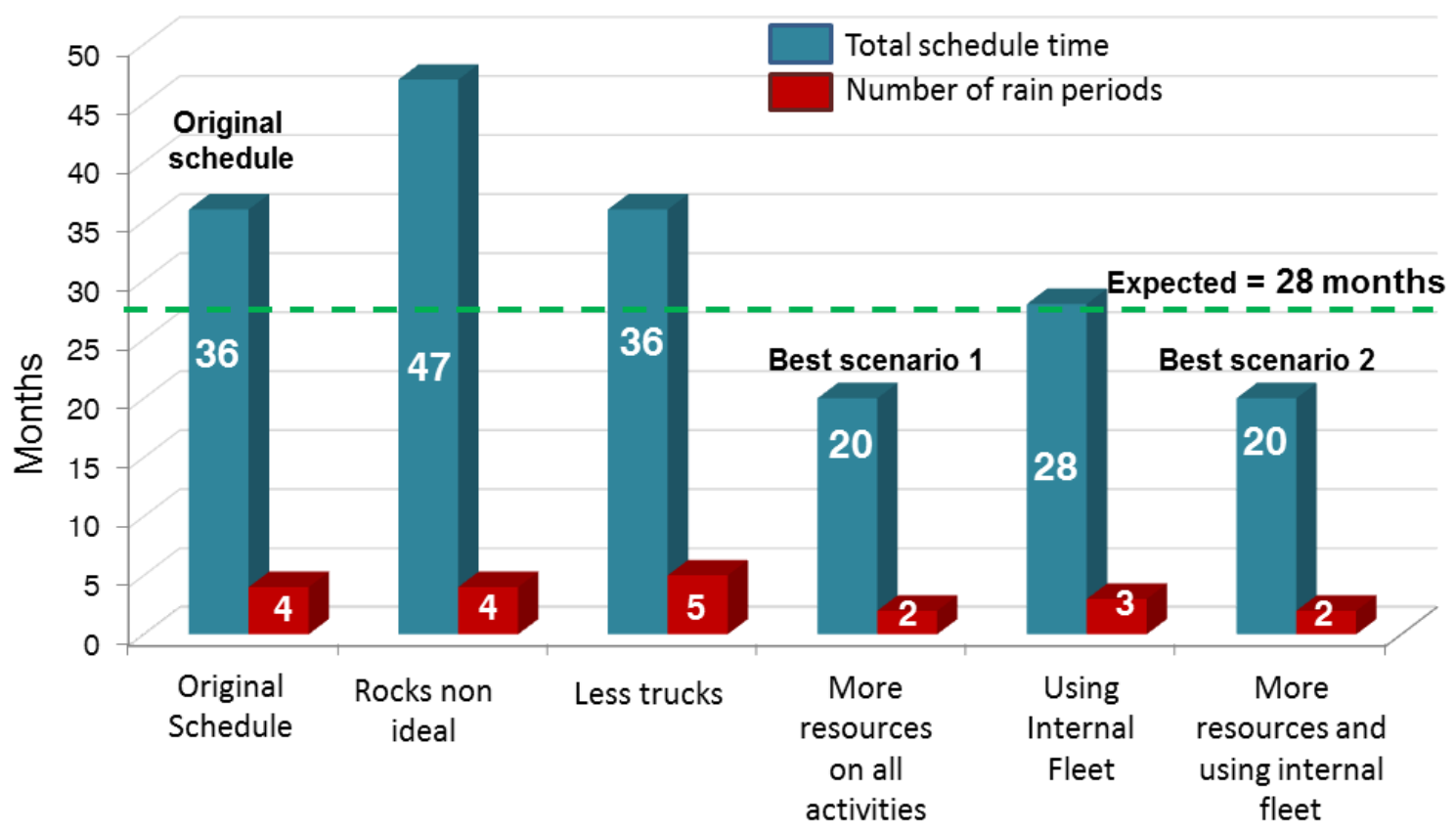

Figure 12: Scenario comparison for the experiments in Phase I.

Experiments in Phase II have tested different alternatives to improve the system. Some scenarios were experimented with a rock stockpile previously prepared. Also, an internal truck fleet could be dedicated to handle this stockpile. The scenarios are presented on Figure 13.

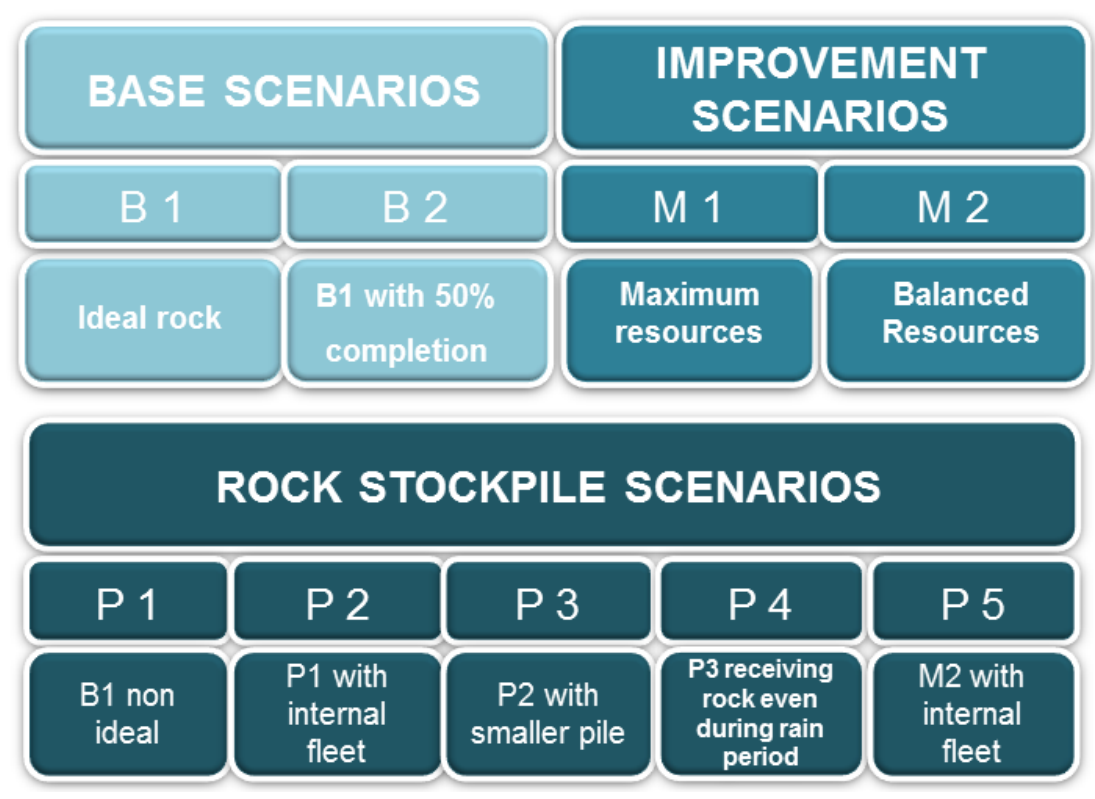

Figure 13: Scenarios experimented in Phase II.

The results of Phase II can be seen in Figure 14. The best scenario was P5, which used a balanced number of resources with stockpile and internal fleet, to end before the due date. Scenario M1 was the best considering the ending date, but had higher cost and low resource utilization. 


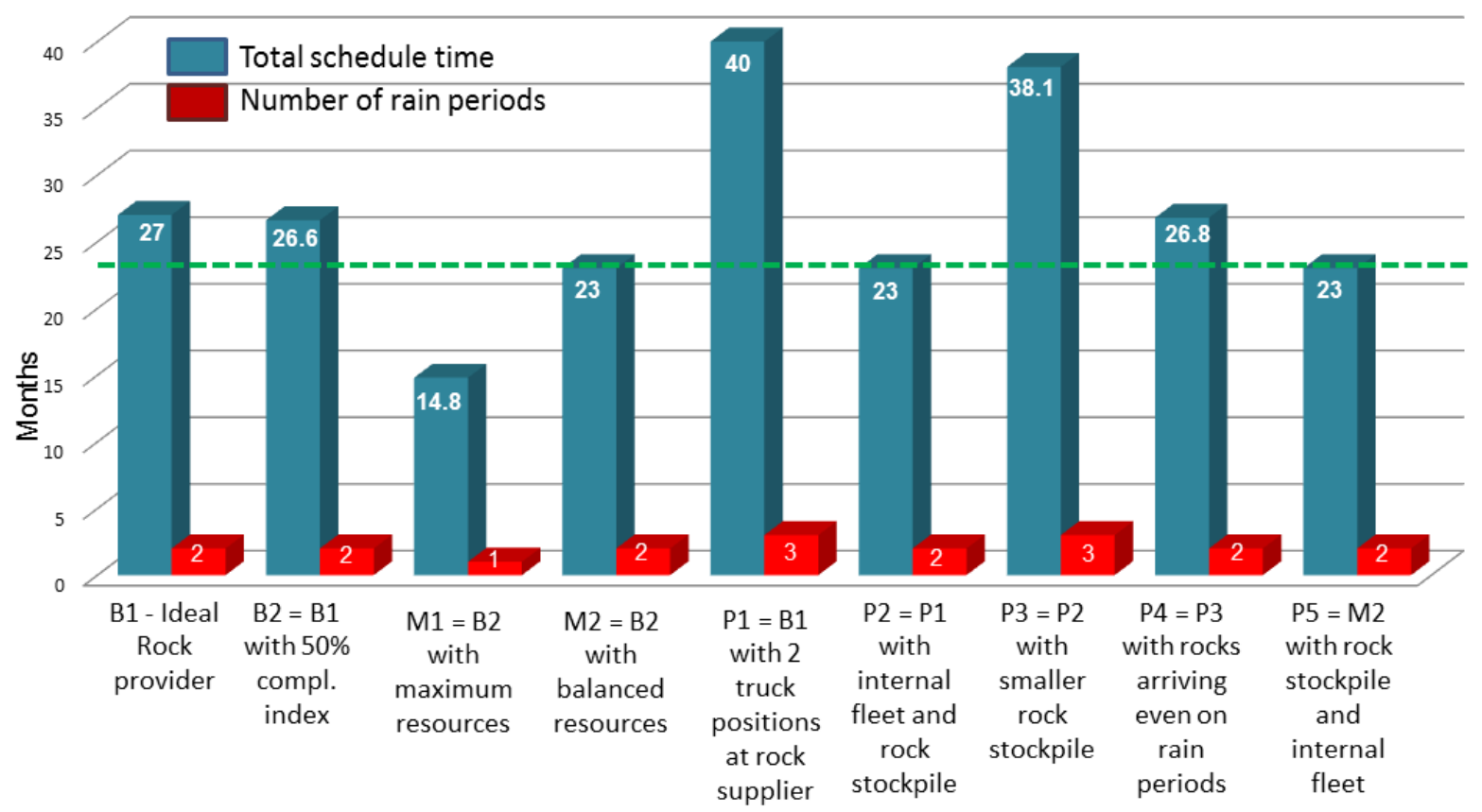

Figure 14: Results comparison for Phase II.

\section{CONCLUSIONS}

In the challenge to set up the country's infrastructure for the World Cup in 2014 and Olympics in 2016, Brazilian government had to expand the greatest and most important airport of Brazil: GRU Airport. The replacement soil work should end in 28 months, on time for the events. This study used simulation to evaluate the original schedule and discovered alternatives to finish the work sooner, potentially in 23 months.

The simulation study allowed army engineers to identify problems that were outside the system, but could impact the work, like the rock providers. Several alternatives were tested, and the scenarios were evolved until reaching the best option.

The importance of considering surrounding aspects of the system were evident in this study, since the worst problems, like road traffic and providers, were outside the system and not considered in the schedule. The original schedule was optimistic regarding these aspects, like every schedule should be, but the outside factors can have great impact to the due date and should be evaluated with a tool like simulation.

The simulation tool developed for this specific study can be reused to evaluate other similar systems regarding soil replacement. Its "core" is the scheduling simulator, and the user can change many parameters, applying it to other geometries. All other aspects, including the animation, should probably be removed from the model because they are very specific for this case.

The most important result of this study was finding a schedule ending earlier than initially planned. This saved time and money, assuring the airport will be ready in 2014. At the time this paper is being written, the soil replacement work is done, and it finished exactly at the planned due date, gathering a lot of attention from the press and news media in general. 
Fioroni, Franzese, Costa, and Kuhn

\section{ACKNOWLEDGMENTS}

This simulation study was more than a regular project for Paragon, since it had great importance for the country. We were professionally committed to it, as always, but also committed as Brazilian citizens. The authors thank the Brazilian Army by supporting this project and for authorizing the use of its information.

\section{REFERENCES}

Bapat, V., and D. T. Sturrock. 2003. "The Arena Product Family: Enterprise Modeling Solutions" In Proceedings of the 2003 Winter Simulation Conference, edited S. Chick, P. J. Sánchez, D. Ferrin, and D. J. Morrice, 210-217. Piscataway, New Jersey: Institute of Electrical and Electronics Engineers, Inc.

Gómez, A. G. 2010. "Simulación de Procesos Constructivos". Revista Ingeniería de Construcción v.25 01:121-141. Pontificia Universidad Javeriana. Colombia.

Ji, Y., A. Borrmann, E. Rank, J. Wimmer, and W. A. Günthner. 2009. "An Integrated 3D Simulation Framework for Earthwork Processes". In Proceedings of the 26th CIB-W78 Conference on Managing IT in Construction. Istanbul, Turkey.

Lucko, G., K. Swaminathan, P. C. Benjamin, and M. G. Madden. 2009. "Rapid Deployment of Simulation Models for Building Construction Applications." In Proceedings of the 2009 Winter Simulation Conference, edited by M. D. Rossetti, R. R. Hill, B. Johansson, A. Dunkin and R. G. Ingalls, 27332744. Piscataway, New Jersey: Institute of Electrical and Electronics Engineers, Inc.

Schramm, F. K., and C. T., Formoso. 2007. "Uso de Simulação Interativa Visual no Projeto de Sistemas de Produção de Empreendimentos da Construção Civil". In Proceedings of the III Encontro de Informação e Comunicação na Construção Civil. Porto Alegre, Rio Grande do Sul, Brazil, 2007.

Tang, P., D. Cass, and A. Mukherjee. 2011. "Using Schedule Simulation Approaches to Reduce Greenhouse Gas Emissions in Highway Construction Project." In Proceedings of the 2011 Winter Simulation Conference, edited by S. Jain, R. R. Creasey, J. Himmelspach, K. P. White, and M. Fu, 805-815. Piscataway, New Jersey: Institute of Electrical and Electronics Engineers, Inc.

\section{AUTHOR BIOGRAPHIES}

MARCELO MORETTI FIORONI is a simulation consultant with an Electrical Engineering degree, MSc. in Manufacturing and PhD in Logistics at University of São Paulo (USP). Has participated in almost 400 successful projects with simulation. Co-founder of PARAGON Tecnologia in 1992, the pioneer and leading consulting company in simulation in South America. Teaches Simulation at Faculdades Metropolitanas Unidas (FMU) in São Paulo, Brazil. Has trained more than 1,200 professionals in simulation. He can be contacted by email at marcelo@paragon.com.br.

LUIZ AUGUSTO G. FRANZESE is a simulation consultant with a Production Engineering degree and MSc. in Logistics, who has completed almost 400 successful projects with simulation. CEO and Founder of PARAGON Tecnologia in 1992, the pioneer and leading consulting company in simulation in South America. Has trained more than 1,200 professionals in simulation. He can be contacted by email at augusto@paragon.com.br.

MARCELLO COSTA is an infrastructure engineer with over 20 years expertise in road and airport's planning and construction. Has a Master Business Administration in Project Management at Fundação Getúlio Vargas (FGV/BR). In 2012 was the project manager of Guarulhos International Airport's expansion using Arena's software on modeling and logistics of work site. He can be contacted by email at marcello_costa@ibest.com.br. 
ANDRE KUHN is the General Coordinator of DNIT- Departamento Nacional de Infraestrutura de Transportes. He has a Civil Engineering degree from Instituto Militar de Engenharia (IME), a degree in Military Sciences at Academia Militar das Agulhas Negras (AMAN) and MSc. in Civil Engineering at Universidade Federal Fluminense (UFF). He was a researcher at Engineer Research and Development Center (ERDC) at USACE. He has been teaching Civil Engineering at several Brazilian universities for almost 13 years. His email address is andre.kuhn@dnit.gov.br. 